\title{
Cytogenetic research in wild animals at FCAVJ, Brazil. I. Mammals
}

\author{
ML Giannoni, JMB Duarte, RP Ribeiro, JF Lui, P Tosta \\ Faculdade de Ciencias Agrarias e Veterinaria (FCAVJ), \\ UNESP 14870, Jaboticabal, São Paulo, Brazil
}

(Proceedings of the 9th European Colloquium on Cytogenetics of Domestic Animals; Toulouse-Auzeville, 10-13 July 1990)

cytogenetics / wild mammals / Brazil

The Center of Study and Research in Wild Animals Prof MA Giannoni, established at FCAVJ, is conducting research projects in mammals and birds. Partial results of cytogenetic analysis of some of these projects are presented below.

The metaphases were obtained as described by Moorhead et al (1960), and chromosome G-, C- and NOR (nucleolar organizer region)-banding patterns were prepared according to Seabright (1971), Sumner (1972) and Howell and Black (1980), respectively.

\section{Cytogenetic analysis of Agouti paca}

This is a subproject of the 'Biology, behavior and adaptation to captivity of the Agouti paca species'. The species has great potential to be explored in animal production, but studies with a conservational viewpoint on repopulation and genetic improvement are needed. The purpose of this investigation was to contribute to the knowledge of the biology of the species, by providing information on the normal karyotype and description of chromosomal banding patterns. The only karyotype description of this species was made by Fredga (1966) but there are persisting doubts concerning the morphology of several chromosomes, including the sex chromosomes. A paca is considered to be a single species throughout Latin America, ranging from Mexico to the Antilles, except in the high and cold regions of the Andes where the species Agouti taczano wskii is found.

In the animals analyzed to date, the karyotype observed was $2 n=74, F N=98$. The metacentric $\mathrm{X}$ and the submetacentric $\mathrm{Y}$ are, respectively, the largest and smallest chromosomes of the karyotype. A variation between 3 and 8 NOR-bands has been observed, and the pericentromeric regions of all chromosomes, including the sex chromosomes, have a positive C-band. Figure 1.1 demonstrates the female karyotype and the inset shows the sex chromosomes of the male $A$ paca. 


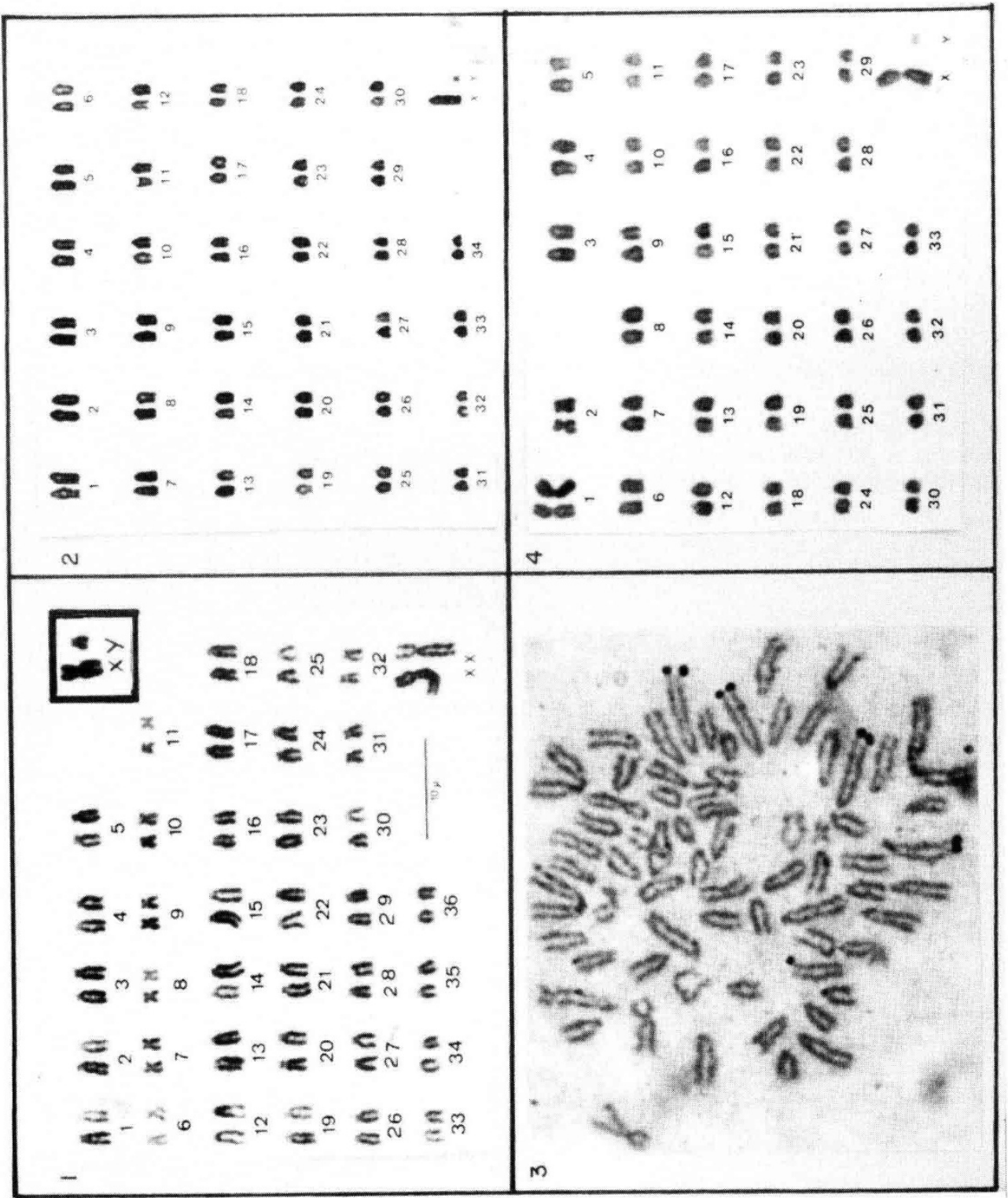

号 


\section{Cytogenetic analysis of Brazilian cervines}

This is a subproject of a larger project on cervines. In addition to the karyotaxonomic comparisons of the 6 Brazilian cervine species, the results of this cytogenetic analysis will be used to select the animals that will supply semen to a 'sperm bank', to be used for the reproduction and preservation of these species. Some of these species, for example the Pantanal deer (Blastoceros dichotomus) and the 'campeiro' deer (Ozotoceros bezoarticus) are threatened by extinction (IUCN Conservation Monitoring Centre, 1988). So far, the analyses have included 8 specimens of Mazama gouazoubira, $2 n=70 ; 3$ Ozotoceros bezoarticus, $2 n=68 ; 1$ Blastoceros dichotomus, $2 n=68 ; 2$ Mazama americana, one with $2 n=56$ and the other with $2 n=40$, and 2 Mazama rufina, one with $2 n=44$ and the other with $2 n=37$, probably heterozygous for a centric fission/fusion chromosome. These results are different from those found in the literature, in terms of chromosome number and/or morphology. Taylor et al (1969) and Jorge and Benirschke (1977) found $2 n=68$ and $2 n=50$, respectively, in the Mazama americana species. The chromosome number in Ozotoceros bezoarticus but not the chromosome morphology, is in agreement with results reported by Bogenberger et al (1987). Also, the chromosome number of Blastoceros dichotomus deviates from the one described by Bogenberger et al (1987). One or two B chromosomes were observed in 2 of the 8 Mazama gouazoubira specimens that were analyzed. The occurrence and frequency of these chromosomes are now being studied. The sample is being enlarged and the G-, C- and NOR-band patterns will be established. Figure 1 (2,3 and 4) show the karyotype of a male Mazama gouazoubira, metaphases with NOR-bands and the karyotype of a male Ozotoceros bezoarticus, respectively.

\section{REFERENCES}

Bogenberger JM, Neitzel H, Fittler F (1987) A highly repetitive DNA component common to all Cervidae: its organization and chromosomal distribution during evolution. Chromosoma $95,154-161$

Fredga K (1966) Chromosome studies in five species of South American rodents (suborder Hystricomorpha). Mamm Chromosomes Newslett 20, 45-46

Howell WM, Black DA (1980) Controlled silver-staining of nucleolus organizer regions with a protective colloidal developer: a 1-step method. Experientia 26, 1014-1015

IUCN Conservation Monitoring Centre (1988) IUCN red list of threatened animals. IUCN Jorge W, Benirschke K (1977) Centromeric heterochromatin and G-banding of the Red Brocket Deer, Mazama americana temana (cervoidea artiodactyla) with a probable nonRobertsonian translocation. Cytologia 42, 711-721

Moorhead PS, Nowell PC, Mellman WJ, Battipps DM, Hungerford DA (1960) Chromosome preparations of leukocytes cultured from human peripheral blood. Exp Cell Res 20, 613-616

Seabright M (1971) A rapid banding technique for human chromosomes. Lancet ii, 971-972 Sumner AT (1972) A simple technique for demonstrating centromeric heterochromatin. Exp Cell Res 75, 304-306

Taylor KM, Hungerford DA, Snyder RL (1969) Artiodactyl mammals: their chromosome cytology in relation to patterns of evolution. In: Comparative Mammalian Cytogenetics (Benirschke K, ed) Springer-Verlag, New York, 346-356 